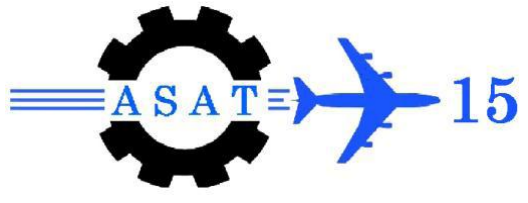

\title{
Mathematical Modeling and Simulation of an Electro-Hydraulic Control System for Plough Machine Operation
}

\author{
M. Rafat ${ }^{*}$, H. A. Abdelkader ${ }^{*}$, M. E. Abo-Elnor ${ }^{*}$, M. H. Said ${ }^{\dagger}$
}

\begin{abstract}
A detailed procedure of the mathematical modeling of an electro-hydraulic control system has been designed to control the demining depth of a mine plough machine equipped with plough blade of "V" type. A Linear Variable Differential Transformer (LVDT) is used to account for blade position and an ultrasonic distance sensor is used to provide precise, noncontact, level distance measurements through dusty environment. The proposed and implemented hydraulic and electronic control systems are described, in order to model the global system dynamics. Matlab/Simulink ${ }^{\circledR}$ program, which is a software package, is used for modelling, simulation, and dynamic analysis. Simulink provides a graphical user interface for building models as block diagrams.
\end{abstract}

The proposed control system is implemented to the operating hydraulic system of a scaled model of a plough mechanism. The operating hydraulic actuators used to control the plough mechanism are controlled through a microcontroller and system relays to maintain plough blade depth constant. Results show that significant match between simulated and real operating surface topology and clearing depth is validated by the proposed control system.

Keywords: Plough mechanism, depth control, mechanical demining, and earth moving equipment control system.

\section{Introduction:}

Nowadays computer simulation is essential in various technical disciplines. It simulates the physical behaviour of systems and is preferable when measurements are impossible or too costly. Simulation is used to investigate complex mechatronic systems, which are characterized by interactions between mechanical, hydraulic and electronic components. The most requirements in modelling a system are the complete understanding of the performance specifications, physical and operational characteristics of each component in the system.

Manual control ploughing depth is highly depending on operator skills and effected by time delay for plough depth mechanism response. Automatic control of blade depth was considered in several applications using several techniques to maintain blade depth within order. Some of these techniques depend on operator control through joystick and operation control through microprocessor and electro-hydraulic controlled actuators [1 , 2 ,3,4], while other developed techniques depend on sensing blade position and terrain topology according to data created from what so named Inertia Navigation System (INS) [5]. Global Positioning System (GPS) which draws three dimensional terrain paths An electro-hydraulic actuators used to control the blade depth via microprocessor controller [6].

Egyptian Armed Forces, Egypt.

$\dagger \quad$ Ph.D., Helwan University, Mataryia, Egypt. 
A geography altering machine, including onboard computer, stores a reference line and a three dimensional computer model of the desired topography was developed [7]. In this technique, digging/ploughing process is fully automated and hence it may be useful in track train ploughing or an underwater digging.

In this study a mathematical modeling describes the dynamic behavior of a conventional plough machine which modified to be automatically controlled through different terrain topologies. A control system includes an ultrasonic sensor to sense the shape of ground in front of the plough machine. The position of plough blade according to the defined reference is controlled by LVDT. An electronic controller module is designed to receive the required depth of cut from the operator and sensors signals as shown in Fig. (1).

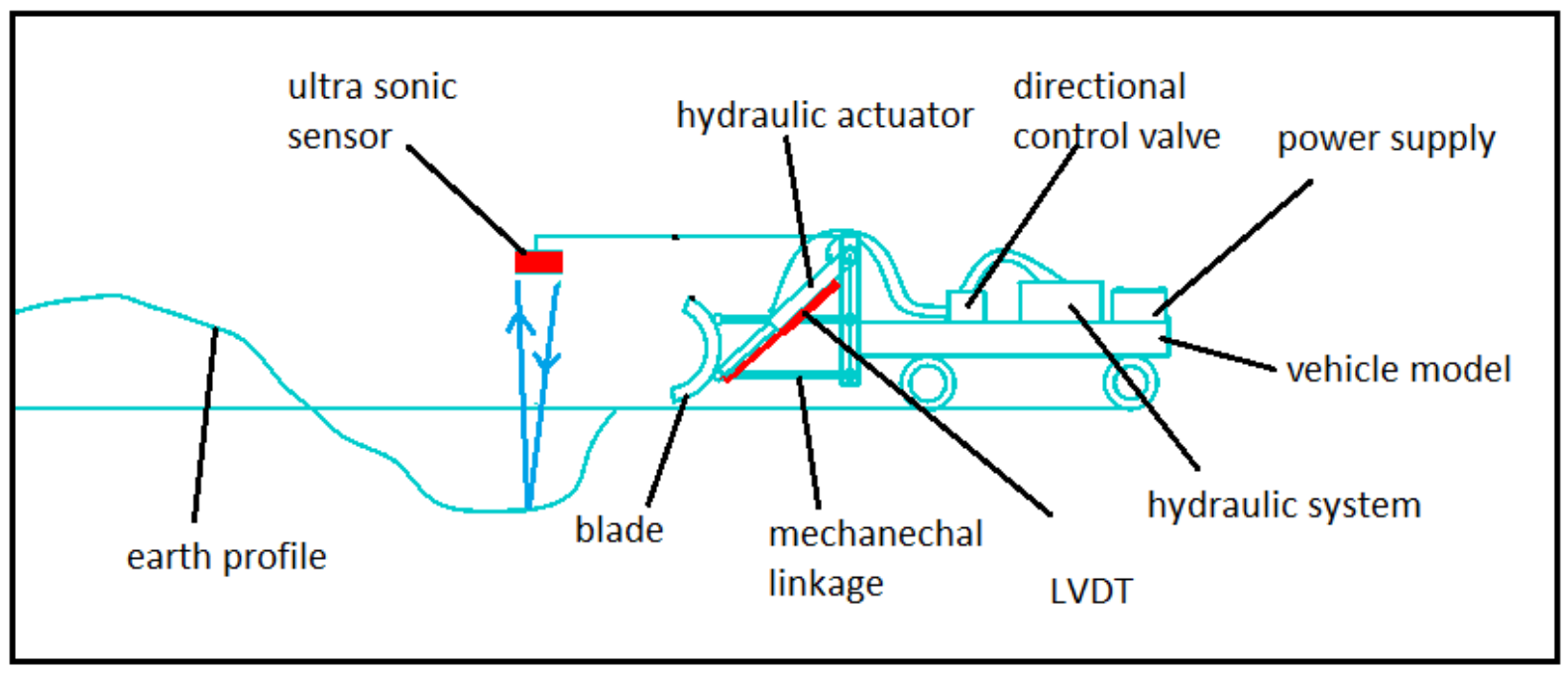

Fig. (1) Proposed control system applied to plough mechanism

\section{Structure and modeling of the system}

A hydraulic cylinder is used as actuator for the plough mine mechanism operation. The depth of cut is controlled according to operator's input and earth profile as shown in Fig. (2).

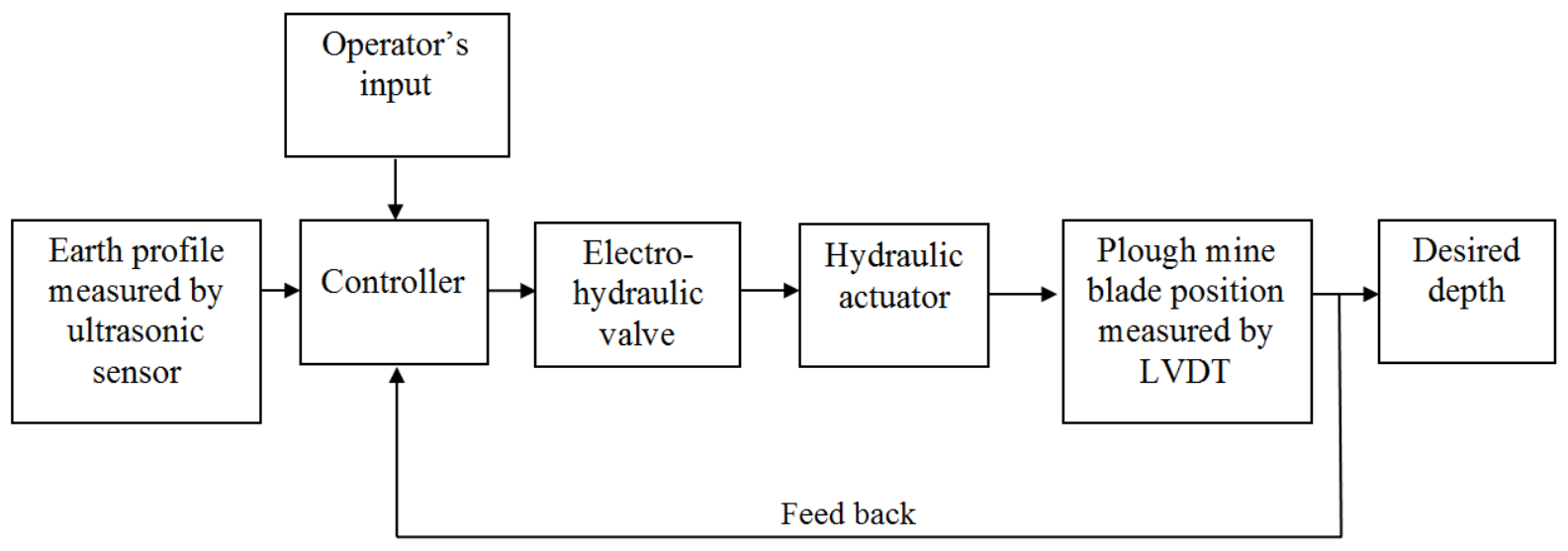

Fig. (2) Plough mine blade position control system block diagram 


\section{Hydraulic subsystem mathematical modeling}

A mathematical model describing the dynamic behavior of studded electro hydraulic directional control valve and hydraulic cylinder actuator.

The input of the system is flow rate of fluid supplied by the pump, and the output is the cylinder displacement as shown in Fig. (3).

The proposed mathematical model is based on the following assumptions:

1- There is no pressure drop in the fluid transmission lines between the pump and valve and between the valve and cylinder.

2- The wave dynamics of fluid is considered constant.

3- The bulk modulus of the fluid is considered constant.

4- There is no leakage at the piston-cylinder interface.

5- The back pressure dynamics are negligible.

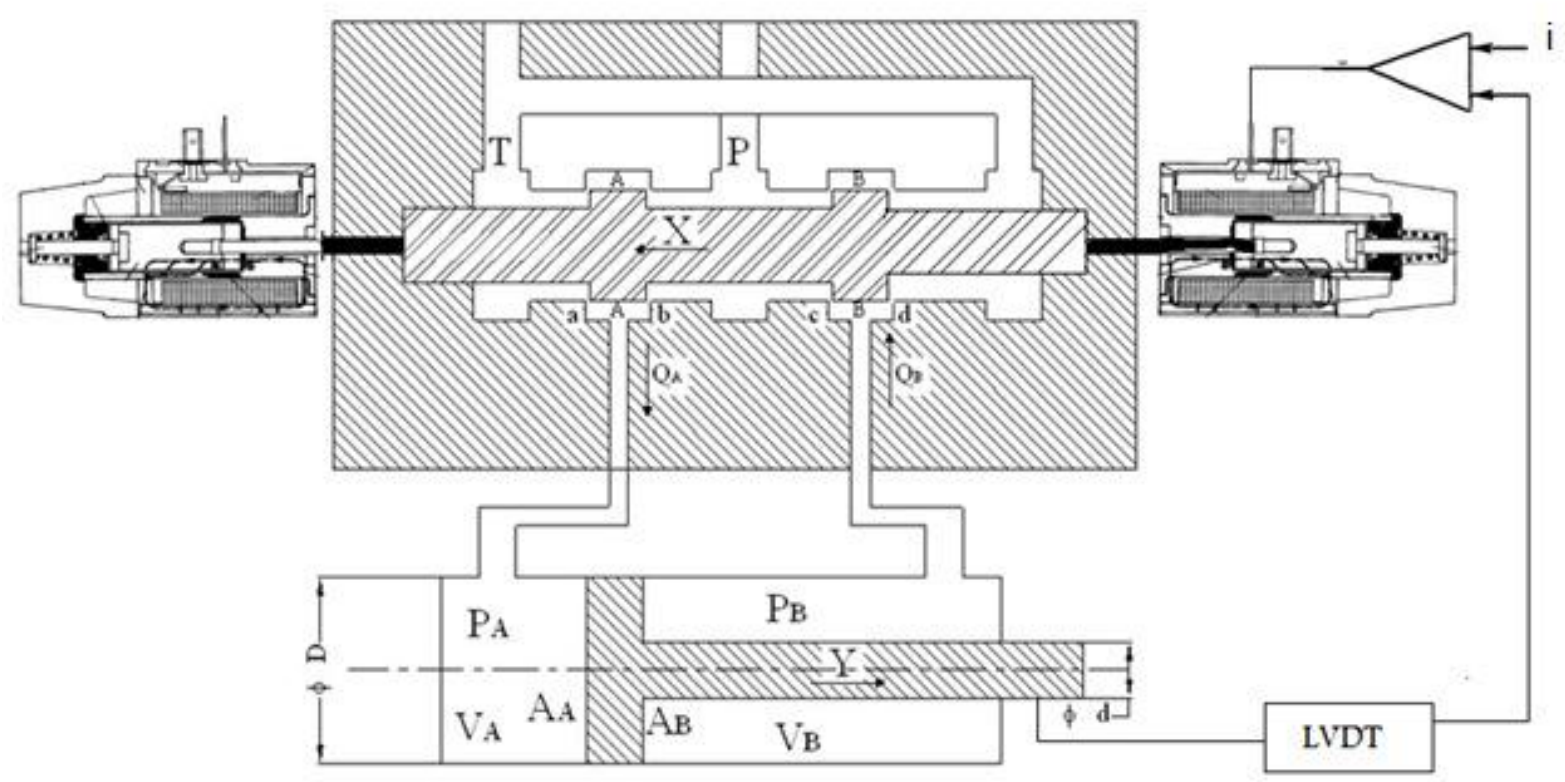

Fig. (3) Schematic diagram of the hydraulic system for numerical simulation

To simulate the valve, it has been divided in two main parts, the solenoid and directional valve block.

\section{Displacement of the valve spool}

The displacement of spool (x) can be calculated from the equation of motion of the spool:

$$
F_{S}=m x+f_{S} x+k_{S} x
$$

where:

$F_{S} \quad$ Solenoid force, $(\mathrm{N})$.

$m \quad$ Spool mass, $\mathrm{kg}$.

$f_{S} \quad$ Friction force per unit velocity, $\mathrm{N} /(\mathrm{m} / \mathrm{s})$.

$k_{S} \quad$ Spool spring stiffness, $\mathrm{N} / \mathrm{m}$. 


\section{Flow equations through valve restriction areas:}

Neglecting the effect of the inner hydraulic transmission lines, the flow rates of the fluid flow throughout the valve restriction areas are given by the following equations:

$$
\begin{aligned}
& Q_{a}=C_{d} A_{a}(x) \sqrt{\frac{2\left(p_{A}-P_{t}\right)}{\rho}} \\
& Q_{b}=C_{d} A_{b}(x) \sqrt{\frac{2\left(p_{s}-P_{A}\right)}{\rho}} \\
& Q_{c}=C_{d} A_{c}(x) \sqrt{\frac{2\left(p_{s}-P_{B}\right)}{\rho}} \\
& Q_{d}=C_{d} A_{d}(x) \sqrt{\frac{2\left(p_{B}-P_{t}\right)}{\rho}}
\end{aligned}
$$

where:

Q Flow rate, $\mathrm{m}^{3} / 3$.

$\mathrm{C}_{\mathrm{d}} \quad$ Discharge coefficient.

A Restriction areas, $\mathrm{m}^{2}$.

$\rho \quad$ Fluid density, $\mathrm{Kg} / \mathrm{m}^{3}$.

$\mathrm{P}_{\mathrm{S}} \quad$ Supply pressure, $\mathrm{pa}$.

$\mathrm{P}_{\mathrm{t}} \quad$ Return pressure, $\mathrm{pa}$.

$\mathrm{x} \quad$ Valve spool opening displacement, $\mathrm{m}$.

For $\mathrm{x} \geq 0$

$$
\begin{gathered}
A_{a}=A_{c}=\omega \sqrt{\left(x^{2}+c^{2}\right.} \\
A_{b}=A_{d}=A_{r}=\omega c
\end{gathered}
$$

For $\mathrm{x} \leq 0$

$$
\begin{gathered}
A_{a}=A_{c}=A_{r}=\omega c \\
A_{b}=A_{d}=\omega \sqrt{\left(x^{2}+c^{2}\right.}
\end{gathered}
$$

where:

$\omega \quad$ Width of the port, $\mathrm{m}$.

c Spool radial opening clearance, $m$.

$\mathrm{x} \quad$ Valve spool opening displacement, $\mathrm{m}$.

$\mathrm{A}_{\mathrm{r}} \quad$ Radial clearance area, $\mathrm{m}^{2}$.

\section{Continuity equation applied to the cylinder chambers}

Actually, the deformation of cylinder wall material is negligible, compared with the oil volumetric variation due to oil compressibility. Then, neglecting the effect of the inner conduits and assuming that the piston is initially at its mid position, the application of continuity equation to the cylinder chambers yields the following equations. 


$$
\begin{aligned}
& Q_{A}-A_{A} \frac{d y}{d t}-Q_{i}-Q_{e A}=\frac{V_{A}}{B}\left(\frac{d P_{A}}{d t}\right) \\
& A_{B} \frac{d y}{d t}+Q_{i}-Q_{B}-Q_{e B}=\frac{V_{B}}{B}\left(\frac{d P_{B}}{d t}\right)
\end{aligned}
$$

The flow rates of QA and QB are given by:

$$
\begin{aligned}
& Q_{A}=Q_{b}-Q_{a} \\
& Q_{B}=Q_{d}-Q_{c}
\end{aligned}
$$

The volumes $\mathrm{V}_{\mathrm{A}}$ and $\mathrm{V}_{\mathrm{B}}$ are given by:

$$
\begin{aligned}
& V_{A}=V_{A 0}+A_{A} y \\
& V_{B}=V_{B 0}+A_{B} y
\end{aligned}
$$

Assuming that the leakage flow rate is linearly proportional to the pressure difference, the leakage flow rates could be given by the following relations:

$$
\begin{gathered}
Q_{i}=\left(P_{A}-P_{B}\right) / R_{i} \\
Q_{e A}=P_{A} / R_{e} \\
Q_{e B}=P_{B} / R_{e}
\end{gathered}
$$

where:

$\mathrm{A}_{\mathrm{A}} \quad$ Piston area of cab side, $\mathrm{m}^{2}$.

$\mathrm{A}_{\mathrm{B}} \quad$ Piston area of rod side, $\mathrm{m}^{2}$.

$\mathrm{Q}_{\mathrm{e}} \quad$ External leakage flow rate, $\mathrm{m}^{3} / \mathrm{s}$.

$\mathrm{Q}_{\mathrm{i}} \quad$ Internal leakage flow rate, $\mathrm{m}^{3} / \mathrm{s}$.

$\mathrm{R}_{\mathrm{e}} \quad$ Resistance to External leakage, $\mathrm{Pa} \mathrm{s} / \mathrm{m}^{3}$.

$\mathrm{R}_{\mathrm{i}} \quad$ Resistance to internal leakage, $\mathrm{Pa} \mathrm{s} / \mathrm{m}^{3}$.

$\mathrm{V}_{\mathrm{A}} \quad$ Volume of oil filling the cylinder at cab side, $\mathrm{m}^{3}$.

$V_{B} \quad$ Volume of oil filling the cylinder at rod side, $\mathrm{m}^{3}$.

B Bulk modulus, pa

$\mathrm{V}_{\mathrm{A} 0} \quad$ Initial volume of cab side, $\mathrm{m}^{3}$.

$\mathrm{V}_{\mathrm{B} 0} \quad$ Initial volume of rob side, $\mathrm{m}^{3}$.

\section{Equation of motion of piston}

The motion of the piston under the action of pressure, viscous friction, inertia, and external forces is described by the following equation:

$$
A_{p}\left(P_{A}-P_{B}\right)=m_{p} \frac{d^{2} y}{d t^{2}}+f_{p}+\frac{d y}{d t}+K_{b} y
$$

where:

$\mathrm{K}_{\mathrm{b}} \quad$ Load coefficient, N/m.

$\mathrm{m}_{\mathrm{p}} \quad$ Mass of piston moving parts, $\mathrm{kg}$.

$\mathrm{f}_{\mathrm{p}} \quad$ Piston friction coefficient, Ns/m. 


\section{Mechanical subsystem kinematics}

The input of the mechanical system is the hydraulic cylinder displacement and the output is a depth of cut. A mathematical model describes kinematic relations which are used mainly in visualization for humans and in forward simulations of the joint trajectories, as shown in Fig. (4).

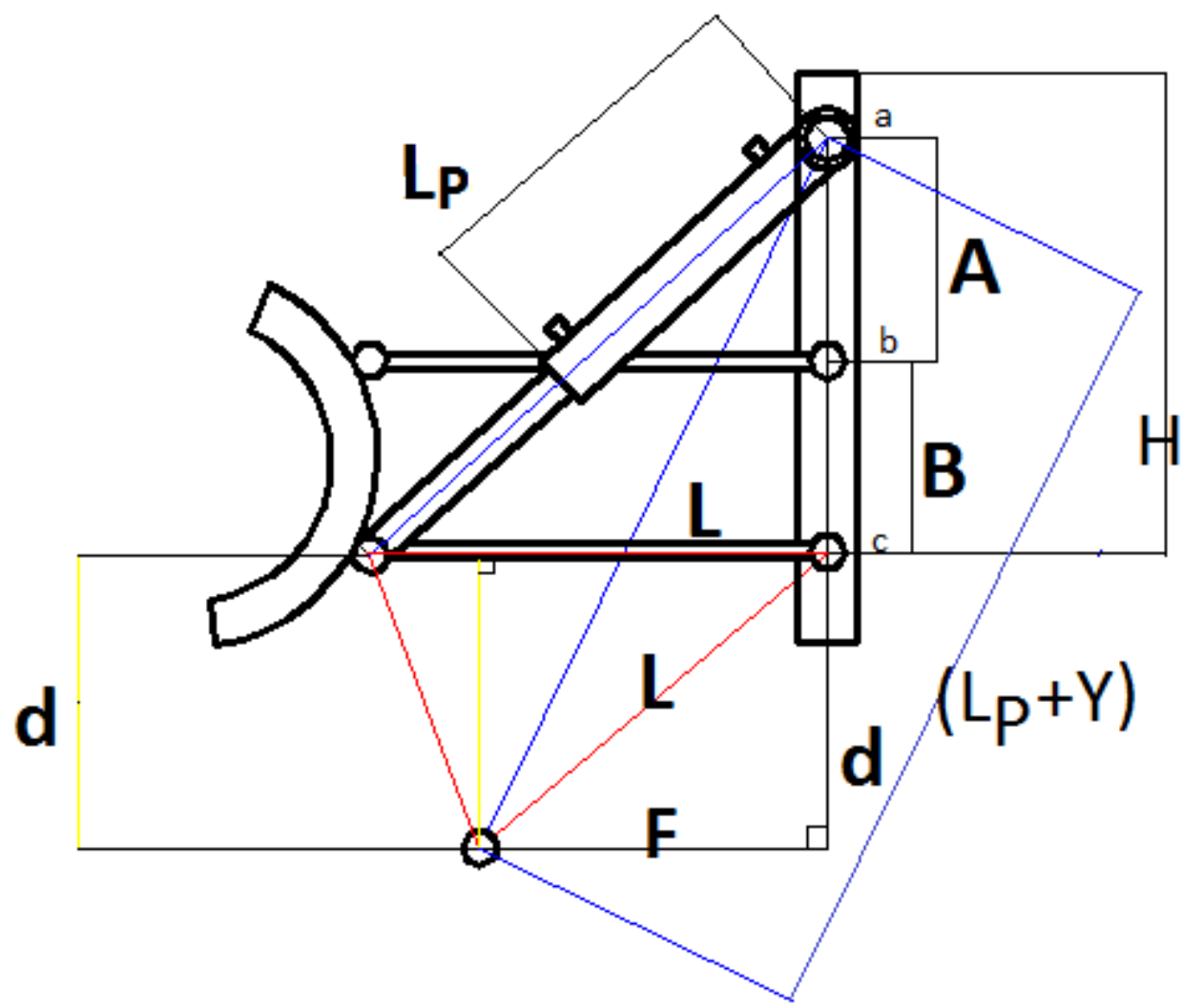

Fig. (4) Plough mine mechanism

Kinematic relations can be described by the following equations:

$$
\begin{gathered}
\left(L_{P}+Y\right)^{2}=F^{2}+(A+B+d)^{2} \\
L^{2}=F^{2}+d^{2} \\
F^{2}=L^{2}-d^{2} \\
\left(L_{P}+Y\right)^{2}=\left(L^{2}-d^{2}\right)+(A+B+d)^{2} \\
\left(L_{P}+Y\right)^{2}=L^{2}-d^{2}+A^{2}+B^{2}+d^{2}+2 A B+2 A d+2 B d \\
\left(L_{P}+Y\right)^{2}=L^{2}+A^{2}+B^{2}+2 A B+2 A d+2 B d
\end{gathered}
$$

Total cylinder length according to required depth of cut can be calculated by the following equation

$$
\left(L_{P}+Y\right)=\sqrt{\left(L^{2}+A^{2}+B^{2}+2 A B+2 A d+2 B d\right)}
$$


The blade depth of cut distance according to given cylinder displacement length can be calculated by the following equation.

$$
d=\frac{\left(\left(L_{P}+Y\right)^{2}-\left(L^{2}+A^{2}+B^{2}+2 A B\right)\right)}{2(A+B)}
$$

Hint, this depth of cut gives an indication of blade position according to joint $\mathrm{c}$.

To make it according to ultrasonic as shown in Fig. (4) holder the equation will be:

$$
d=\left[\frac{\left(\left(L_{P}+Y\right)^{2}-\left(L^{2}+A^{2}+B^{2}+2 A B\right)\right)}{2(A+B)}\right]+H
$$

where $\mathrm{H}$ is the vertical distance between joint $\mathrm{c}$ and the ultrasonic holder level. The inverse relationship provides cylinder displacement necessary to achieve the pose according to given depth of cut can be calculated by the following equation:

$$
Y=\sqrt{\left(L^{2}+A^{2}+B^{2}+2 A B+2 A d+2 B d\right)}-L_{P}
$$

where:

A Distance between joint $\mathrm{a}, \mathrm{b}, \mathrm{cm}$.

B Distance between joint b,c ,cm.

L Link length, $\mathrm{cm}$.

$\mathrm{L}_{\mathrm{P}}$ Cylinder length, $\mathrm{cm}$.

Y Cylinder displacement, $\mathrm{cm}$.

d Depth of cut, cm.

$\mathrm{H}$ Distance between joint $\mathrm{b}$ and ultrasonic holder, $\mathrm{cm}$.

\section{MATLAB Modeling}

The governing equations of the hydraulic and mechanical systems are used in building the simulation of the system, as shown in Figs. $(5,6)$ each subsystem have been built up individually and then they are gathered to form the main system

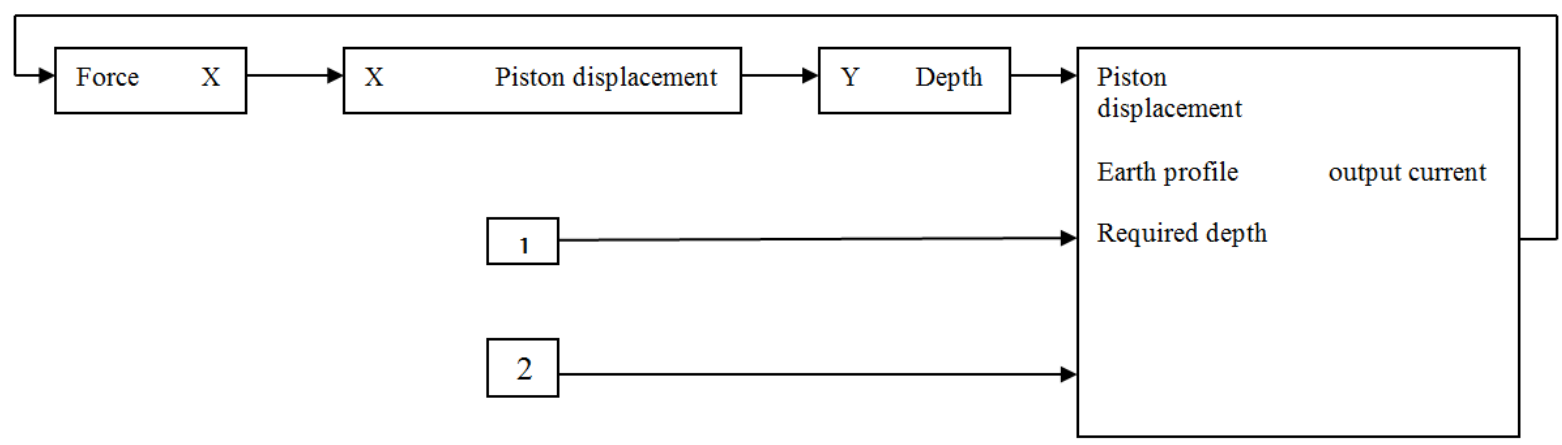

Fig. (5) Plough control system simulink model 


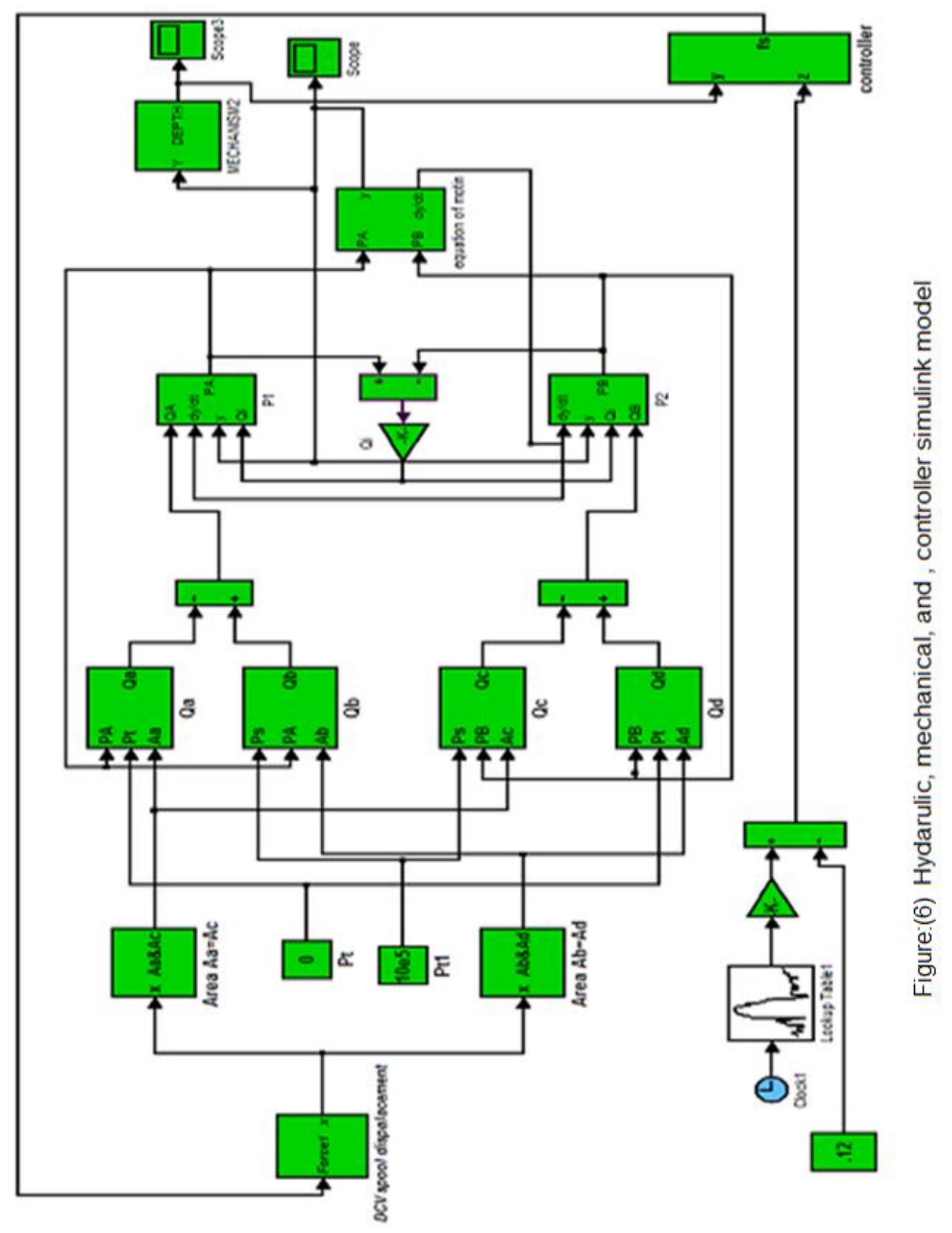




\section{Results and Discussion}

The electronically demining control system has been verified via the mathematical modeling. The system consists of three subsystems; hydraulic, mechanical, and electronic sub systems. The hydraulic subsystem is modeled mathematically; the input signal is the input current of the solenoid valve.

The mechanical subsystem have is integrated with the hydraulic subsystem and they are modeled mathematically the input signal is also the solenoid input current. The hydraulic cylinder of the hydraulic subsystem actuates the mechanical subsystem actuates the mechanical subsystem.

A step response of hydraulic and mechanical sub system at $10 \mathrm{sec}$ of the simulated model is shown in Fig. (7).

The electronic control system is embedded with the integrated hydraulic and mechanical subsystems. The integration of the three subsystems, constructed the proposed control system.

This system is mathematically modeled. The earth profile is the input signal to that system. A control system response of a step input of $15 \mathrm{~cm}$ amplitude at time of $5 \mathrm{sec}$ of the simulated model is shown in Fig. (8).

As a result of Fig. (8);

1- The maximum overshoot is: $\sigma=\frac{\mathrm{y}_{\max } \mathrm{y}_{\mathrm{ss}}}{\mathrm{y}_{\mathrm{ss}}} \times 100 \%=\frac{0.156-0.15}{0.15} \times 100 \%=4 \%$

2- The delay time response to reach $50 \%$ of the final steady state of the system is $0.3 \mathrm{sec}$.

3- The Settling time is $1 \mathrm{sec}$

4- Steady state error $\left[\mathrm{y}_{\mathrm{ss}}-\mathrm{y}(\mathrm{t})\right]$ is calculated as. $1505-.015=.0005=0.3 \%$ of a steady state

Figure (9) shows the result of using a scanned earth profile as a simulated model input with zero required depth of cut.

A result shows very good response of the simulated control system, the simulated control system follows the input scanned profile. An experimental system result for the same earth profile at vehicle speed $3.6 \mathrm{~cm} / \mathrm{s}$ and 0 depth of cut shown in Fig. (10).

Figure (11) shows the result of using another scanned earth profile as a simulated model input with $2 \mathrm{~cm}$ required depth of cut.

A result shows very good response of the simulated control system, the simulated control system follows the input scanned profile. An experimental system result for the same earth profile at vehicle speed $3.6 \mathrm{~cm} / \mathrm{s}$ and $2 \mathrm{~cm}$ depth of cut shown in Fig. (12).

By comparing the experimental and simulated results, it appears that there is a delay in a system response due to suddenly change in an earth profile and there is another delay at a real time case due to construction of a test rig at the time period (25-30) sec. 


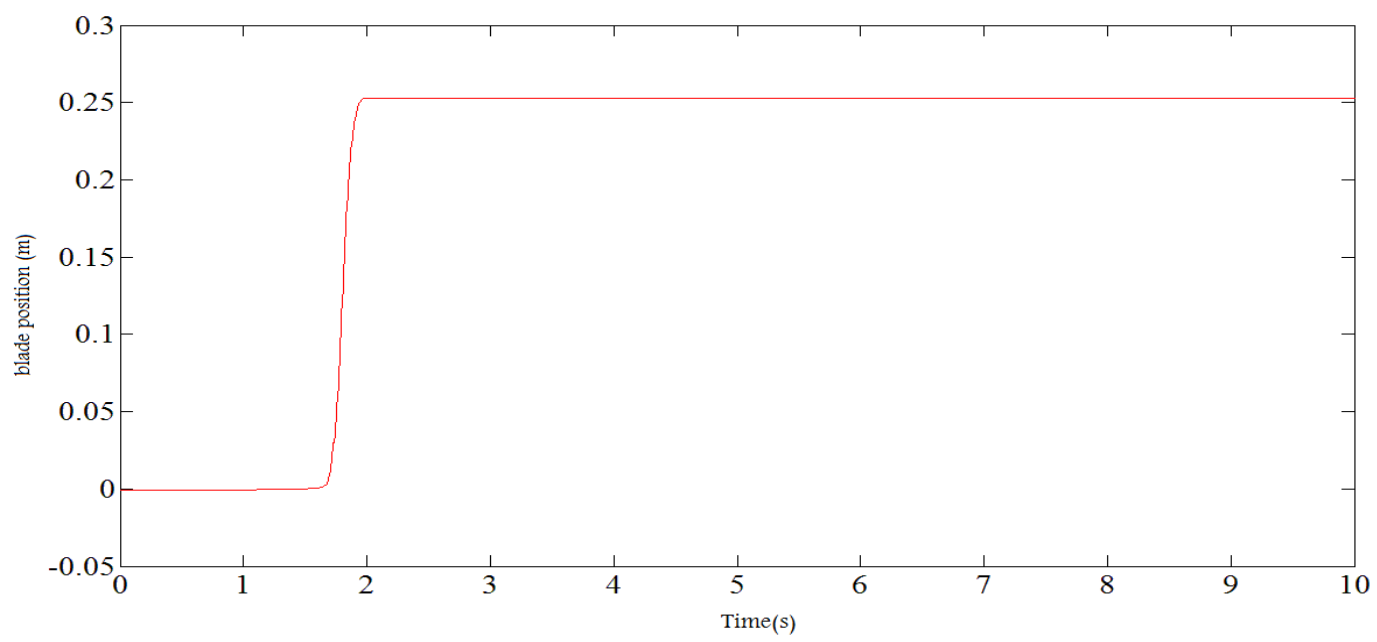

Fig. (7) Step response of the hydraulic and mechanical sub system Simulink model

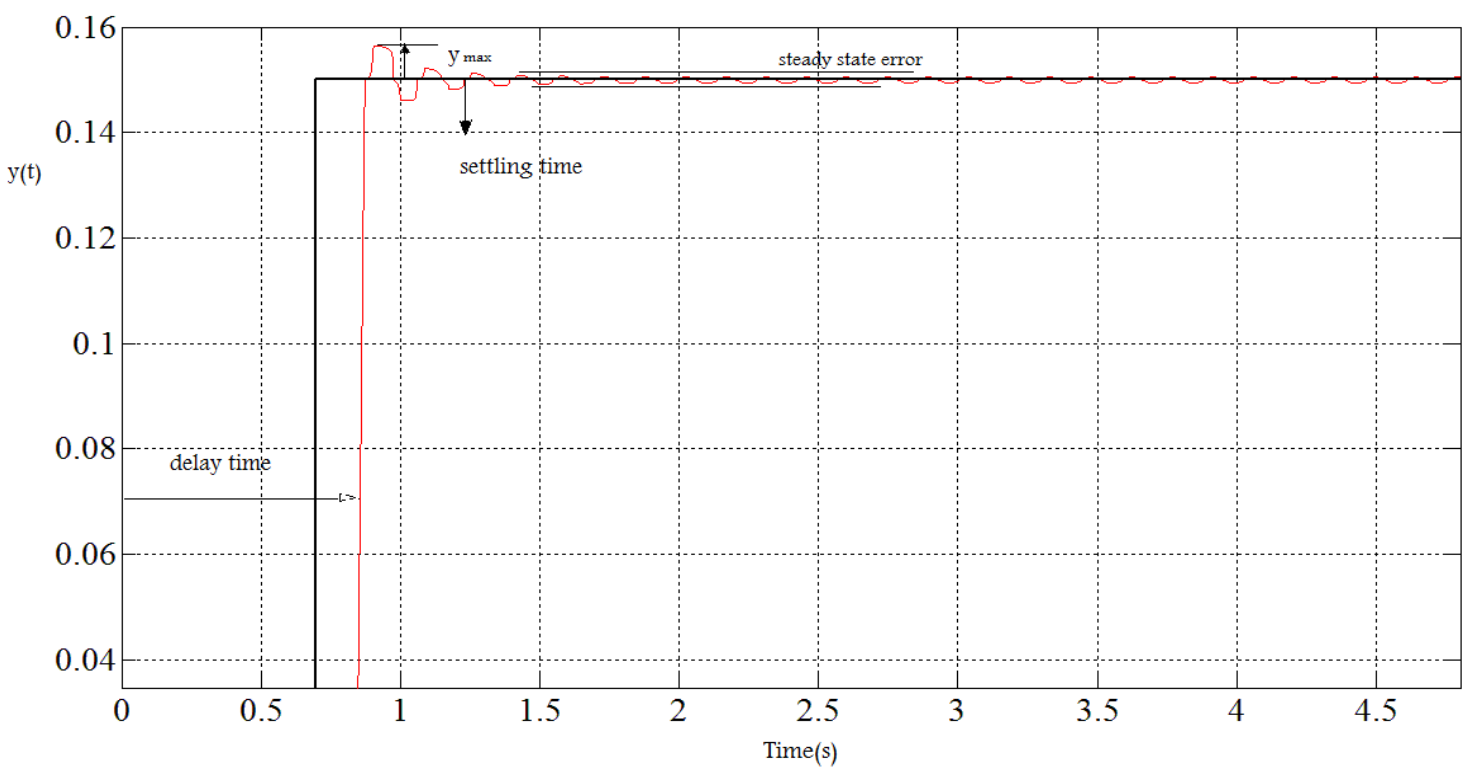

Fig. (8) Control system response simulink model

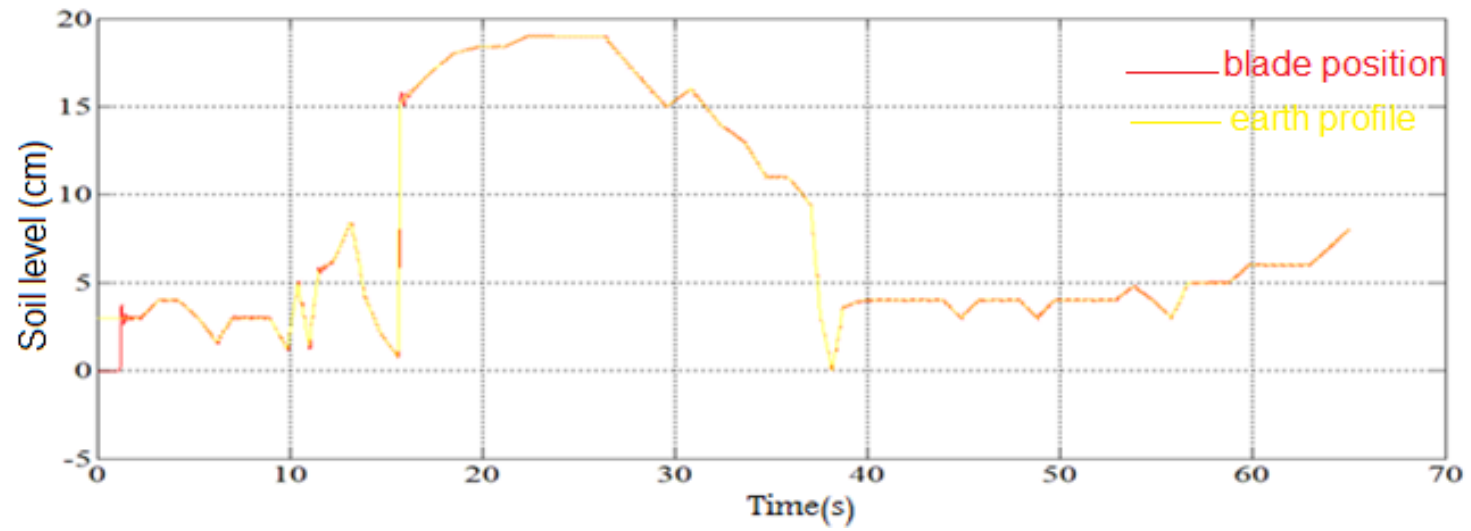

Fig.: (9) Simulated result of control system on earth profile at 0 depth of cut 


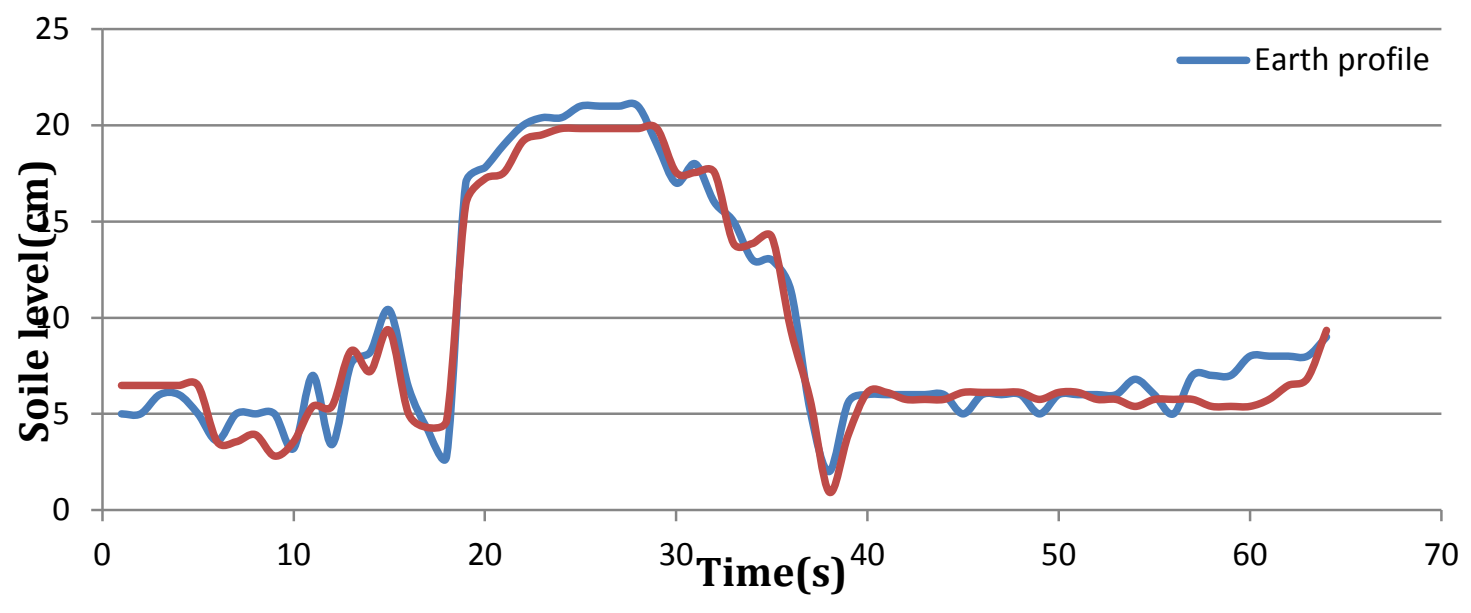

Fig. (10) Experimental result of control system on earth profile at 0 depth of cut Results show a similarity of a real and simulated result for the same earth profile.

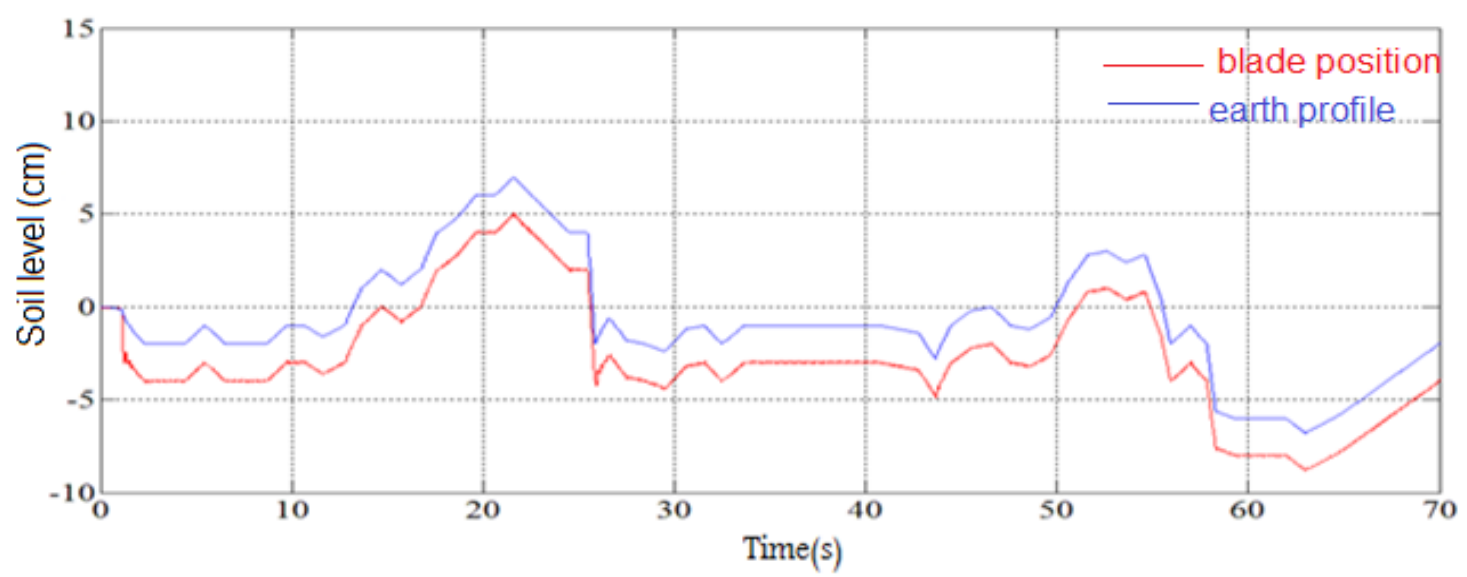

Fig. (11) Simulated result of control system on an earth profile at $2 \mathrm{~cm}$ depth of cut

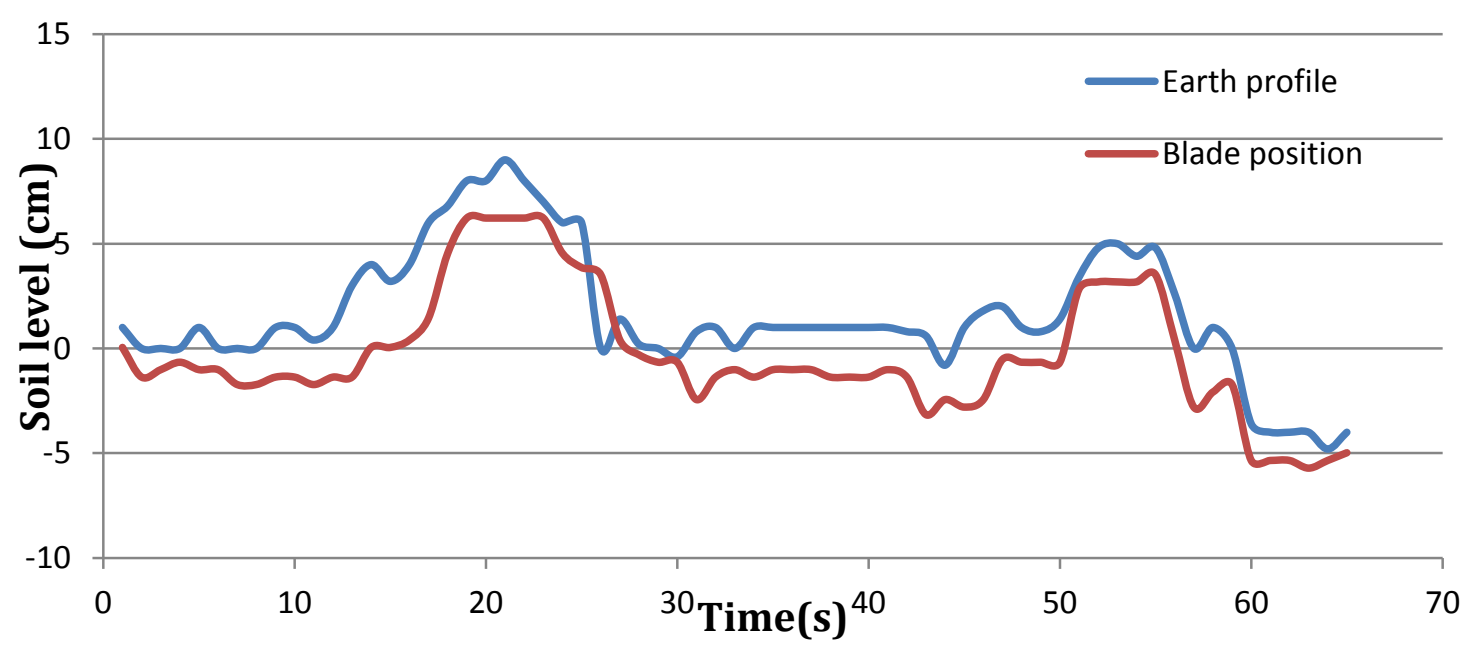

Fig. (12) Experimental result of control system on an earth profile at $2 \mathrm{~cm}$ depth of cut 


\section{Conclusions}

The plough machine electronic control system is verified due to the simulated system results:

1- The maximum overshoot is: $\sigma=\frac{\mathrm{y}_{\max } \mathrm{y}_{\mathrm{ss}}}{\mathrm{y}_{\mathrm{ss}}} \times 100 \%=\frac{0.156-0.15}{0.15} \times 100 \%=4 \%$

2- The delay time response to reach $50 \%$ of the final steady state of the system is $0.3 \mathrm{sec}$.

3- The Settling time is $1 \mathrm{sec}$

4- Steady state error $[\mathrm{yss}-\mathrm{y}(\mathrm{t})]$ is calculated as. $1505-.015=.0005=0.3 \%$ of a steady state .

\section{References}

[1] Igal kasher, kfar Saba,Haim Ginat, Ramat Hasharon "Automotive Earth Moving Vehicle with Segmented Blade for Alternating Between Straight and Angular Shapes", United states patent ,Patent Number 4,909,330, 1990

[2] Cynthia M.Gardener,Rober,t E.Stone,John, D.Duffy,William, E.Allen,Jame, E.Schimpf "Method and Apparatus for Controlling an Implement of a Work Machine ", United states patent , Patent Number5,701,793,1997

[3] Edward C. Hughes, Christopher Alan, Williamson, Joshua D.Zimmerman, Marianne Ivantysynova " System and Method for Blade Level Control of Earthmoving Machines", United states patent, Patent Number016358 2010

[4] Kenneth L.Stratton, Dunlap "Site Profile Based Control System and Method for an Earthmoving Implement', United states patent, Patent Number 5, 560, 431, 1996

[5] R.Bruce Carlson,,David ,Leonid Entov “ Real-time Surveying/Earth Moving System”, United states patent, Patent Number6.191,732, 2001

[6] David S.Carlson, JAMES, Ronald, Frederick "Blade Control Apparatuses and Methods for an Earthmoving Machine', United States patent, Patent Number0162668, 2002

[7] George T.Lumpkins, Peter J. Dix, Daniel B.Shore " Bulldozer Autograding System ', United states patent, Patent Number7,121,355, 2006

[8] M. Galal Rabie “Automatic control for mechanical engineers” McGraw-Hill, 2008. 